\title{
Release of Ecdysteroid-Phosphates from Egg Yolk Granules and Their Dephosphorylation during Early Embryonic Development in Silkworm, Bombyx mori
}

\author{
Ryouichi Yamada ${ }^{1}$, Yumi Yamahama ${ }^{2}$ and Haruyuki Sonobe ${ }^{1,3 *}$ \\ ${ }^{1}$ Department of Life and Functional Material Science, Graduate School of Natural \\ Sciences, Konan University, Kobe 658-8501, Japan \\ ${ }^{2}$ Department of Biology, Hamamatsu University School of Medicine, \\ Hamamatsu 431-3192, Japan \\ ${ }^{3}$ Department of Biology, Faculty of Science and Engineering, Konan \\ University, Kobe 658-8501, Japan
}

\begin{abstract}
Newly laid eggs of many insect species store maternal ecdysteroids as physiologically inactive phosphoric esters. In the silkworm Bombyx mori, we previously reported the presence of a specific enzyme, called ecdysteroid-phosphate phosphatase (EPPase), which catalyzes the dephosphorylation of ecdysteroid-phosphates to increase the amount of free ecdysteroids during early embryonic development. In this study, we demonstrated that (1) EPPase is found in the cytosol of yolk cells, (2) ecdysteroid-phosphates are localized in yolk granules, being bound to the yolk protein vitellin $(\mathrm{Vn})$, and (3) Vn-bound ecdysteroid-phosphates are scarcely hydrolyzed by EPPase, although free ecdysteroid-phosphates are completely hydrolyzed by EPPase. Thus, we investigated the mechanism by which ecdysteroid-phosphates dissociate from the $\mathrm{Vn}$-ecdysteroid-phosphate complex, and indicated that the acidification of yolk granules causes the dissociation of ecdysteroid-phosphates from the $\mathrm{Vn}$-ecdysteroid-phosphate complex and thereby ecdysteroid-phosphates are released from yolk granules into the cytosol. Indeed, the presence of vacuolar-type proton-translocating ATPase in the membrane fraction of yolk granules was also verified by Western blot analysis. Our experiments revealed that $\mathrm{Vn}$ functions as a reservoir of maternal ovarian ecdysteroid-phosphates as well as a nutritional source during embryonic development. This is the first report showing the biochemical mechanism by which maternal Vn-bound ecdysteroid-phosphates function during early embryonic development.
\end{abstract}

Key words: ecdysteroids, phosphatase, V-ATPase, vitellin, embryonic development

\section{INTRODUCTION}

Eggs of many insect species contain various molecular species of ecdysteroids in free and conjugated forms (mainly phosphoric esters) which are synthesized in developing ovaries and accumulated in mature oocytes (Hoffmann and Lagueux, 1985; Hagedorn, 1985; Ohnishi, 1990; Lafont et al., 1995). In the cockroach Blaberus craniifer (Bullière et al., 1979), the migratory locust Locusta migratoria (Lagueux et al., 1979), the tobacco hornworm Manduca sexta (Warren et al., 1986) and the desert locust Schistocerca gregaria (Scalia et al., 1987), egg ecdysteroids are predicted to participate in the regulation of morphological events during embryonic development, since a close tempo-

\footnotetext{
${ }^{*}$ Corresponding author. Phone: +81-78-435-2512;

Fax : +81-78-435-2539;

E-mail: sonobe@konan-u.ac.jp
}

ral correlation has been found between developmental changes of ecdysteroid levels and embryonic events, such as the secretion of serosal cuticle and the formation of embryonic cuticle (embryonic molt). Recently, in the silkworm Bombyx mori, we showed that the continuous supply of 20-hydroxyecdysone (20E) is required for embryonic development, whereas the deficiency in $20 \mathrm{E}$ brings about embryonic diapause during which the embryo ceases development at the late gastrula stage (Makka et al., 2002). In the fruit fly Drosophila melanogaster with embryonic lethal mutations that disrupt developmental processes, including cuticle formation, head involution, dorsal closure and gut morphogenesis, it was demonstrated that all these developmental disruptions are caused by metabolic deletion in $20 \mathrm{E}$ production (Gilbert, 2004).

In $B$. mori eggs, 20E arises from both de novo biosynthesis and dephosphorylation of maternal inactive ecdy- 
steroid-phosphates (Sonobe et al., 1999; Makka and Sonobe, 2000). In the 20E biosynthesis, P450 ecdysone 20hydroxylase, which catalyzes the hydroxylation at C-20 position of ecdysone, was demonstrated to be the rate-limiting step (Horike and Sonobe, 1999; Horike et al., 2000). In the dephosphorylation pathway, we found a novel enzyme ecdysteorid-phosphate phosphatase (EPPase) that specifically catalyzes the dephosphorylation of ecdysteroid-phosphates, whose activity is regulated at the level of transcription (Yamada et al., 2002; Yamada and Sonobe, 2003). In a kinetic study of EPPase, we obtained preliminary results that most of maternal ecdysteroid-phosphates are bound to vitellin $(\mathrm{Vn})$ in vivo, and that EPPase scarcely hydrolyzes Vn-bound ecdysteroid-phosphates, while it easily hydrolyzes free ecdysteroid-phosphates (Sonobe and Yamada, 2004).

The present study was attempted to clarify the mechanism by which Vn-bound ecdysteroid-phosphates are hydrolyzed by EPPase during early embryonic development. Results are discussed in relation to the differences in the mode of $20 \mathrm{E}$ production between diapause eggs and nondiapause eggs of $B$. mori.

\section{MATERIALS AND METHODS}

\section{Insects}

A hybrid race (Kinshu×Showa) of the silkworm B. mori, which had been destined to produce diapause eggs (diapause egg-producers), was used. In diapause eggs, embryos ceased development at the late gastrula stage (48-72 hr after oviposition) (Sonobe et al., 1986; Sonobe and Odake, 1986). In order to obtain nondiapause egg-producers, the subesophageal ganglion, the source of diapause hormone, was removed soon after larval-pupal ecdysis (Fukuda, 1951; Sonobe and Odake, 1986). Nondiapause eggs continued to develop and larvae hatched about 11 days after oviposition. To obtain closely synchronized eggs, eggs laid within $3 \mathrm{hr}$ were pooled and kept at $25^{\circ} \mathrm{C}$ until use.

\section{Extraction of ecdysteroids}

In order to extract ecdysteroids exhaustively from mature oocytes, they were homogenized in $80 \%$ methanol (Rees and Isaac, 1985; Ohnishi et al., 1989; Kamba et al., 1994). The homogenate was centrifuged at $10,000 \mathrm{~g}$ for $15 \mathrm{~min}$ and the resulting pellet was re-extracted twice in the same way. The extracts were combined and used for further analyses. In order to investigate whether ecdysteroids are bound to a certain macromolecule, mature oocytes were homogenized in $10 \mathrm{mM}$ Hepes- $\mathrm{NaOH}$ buffer, $\mathrm{pH} 7.5$, containing $150 \mathrm{mM} \mathrm{NaCl}, 1 \mathrm{mM}$ dithiothreitol (DTT), $0.5 \mathrm{mM}$ phenylmethylsulfonyl fluoride (PMSF), $10 \mu \mathrm{M}$ pepstatin A and $10 \mu \mathrm{M}$ leupeptin (buffer A), and the homogenate was centrifuged at $10,000 \mathrm{~g}$ for $30 \mathrm{~min}$. The resulting supernatant was further centrifuged at $150,000 \mathrm{~g}$ for $60 \mathrm{~min}$. The $150,000 \mathrm{~g}$ supernatant was analyzed by column chromatography as described later.

\section{Quantification of free ecdysteroids and ecdysteroid-phos- phates}

The procedure used to separate free ecdysteroids and ecdysteroid-phosphates was essentially the same as described in our previous papers (Kamba et al., 1994; Mamiya et al., 1995). Briefly, ecdysteroids extracted from eggs were dissolved in a small volume of $30 \%(\mathrm{v} / \mathrm{v})$ methanol in chloroform and applied to a silicic acid column (Bond Elut silica cartridge; Varian, USA) equilibrated with the same solution. The free ecdysteroid fraction and ecdysteroid-phos- phate fraction were eluted with $30 \%$ methanol in chloroform and $80 \%$ aqueous methanol, respectively. An aliquot of the free ecdysteroid fraction was evaporated to dryness under reduced pressure, and used for radioimmunoassay (RIA). In order to quantify ecdysteroid-phosphates by RIA, the ecdysteroid-phosphate fraction was evaporated and dissolved in a small volume of $100 \mathrm{mM}$ acetate buffer, $\mathrm{pH} 5.1$, containing $0.1 \%$ bovine serum albumin (BSA), and incubated with $1 \mu \mathrm{l}$ of digestive juice of the snail Helix pomatia (Nacalai tesque, Japan) for $6 \mathrm{hr}$ at $37^{\circ} \mathrm{C}$ (Ohnishi et. al., 1989; Kamba et al., 1994). The reaction was stopped by the addition of 4 volume of methanol, and the mixture was centrifuged at $10,000 \mathrm{~g}$ for $15 \mathrm{~min}$. An aliquot of the supernatant was evaporated, and used for RIA using an antiserum N-6 generated against 20E-6-carboxymethyloxime hapten (Yamada and Sonobe, 2003). RIA was conducted as described previously (Sonobe et al., 1990).

\section{Detection of Vn-ecdysteroid-phosphate complex}

Mature oocytes $(5.0 \mathrm{~g})$ were dissected from adult moths, and homogenized in $10 \mathrm{mM}$ Hepes- $\mathrm{NaOH}$ buffer $(10 \mathrm{ml})$, $\mathrm{pH} 7.5$, containing $1 \mathrm{mM}$ DTT, $0.5 \mathrm{mM}$ PMSF, $10 \mu \mathrm{M}$ pepstatin A and $10 \mu \mathrm{M}$ leupeptin (buffer $B$ ). The homogenate was centrifuged at $1,000 \mathrm{~g}$ for $10 \mathrm{~min}$ to remove chorion fragments. The supernatant was centrifuged at $10,000 \mathrm{~g}$ for $30 \mathrm{~min}$. The resulting supernatant was further centrifuged at $150,000 \mathrm{~g}$ for $60 \mathrm{~min}$. An aliquot of $150,000 \mathrm{~g}$ supernatant was loaded onto a $Q$ Sepharose HP column (Amersham Bioscience, USA), pre-equilibrated with buffer $A$. Proteins were eluted by a linear gradient of 0 to $500 \mathrm{mM} \mathrm{NaCl}$ in buffer $\mathrm{B}$ for 90 min at a flow rate of $2.5 \mathrm{ml} / \mathrm{min}$. Fractions containing ecdysteroid-phosphates were pooled, concentrated, and loaded onto a HiLoad 16/60 Superdex 200 pg column (Amersham Bioscience). All procedures were carried out at $4^{\circ} \mathrm{C}$. Ecdysteroid-phosphates in each fraction were extracted with $80 \%$ methanol and measured by RIA as described above. The procedures of SDS-PAGE analysis and Western blot analysis using anti- $\mathrm{Vn}$ antibody were essentially the same as described in our previous paper (Yamada and Sonobe, 2003).

\section{Immunohistochemistry}

Nondiapause eggs collected at $72 \mathrm{hr}$ after oviposition were fixed with Bouin's solution for $3 \mathrm{hr}$ and their chorions were removed using needles. The eggs were dehydrated passing through an ethanol-butanol series, embedded in paraffin, and sectioned at $5 \mu \mathrm{m}$. Paraffin was removed from the sections with xylene. The sections were incubated with anti-recombinant EPPase antibody (Yamada and Sonobe, 2003) (1:1000 dilution with phosphate buffered saline, $\mathrm{pH} 7.5$, containing $1 \% \mathrm{BSA}$ ) or anti- $\mathrm{Vn}$ antibody (1:3000 dilution with phosphate buffered saline, $\mathrm{pH} 7.5$, containing $1 \% \mathrm{BSA}$ ) for 1 $\mathrm{hr}$ at $25^{\circ} \mathrm{C}$, and then incubated with goat anti-rabbit peroxidase-conjugated immunoglobulin (IgG) (Histofine Simple Stain MAX-Po(R); Nichirei, Japan). The peroxidase activity was visualized with 3,3'diaminobenzidine tetrahydrochloride (DAB) solution (Simple Stain DAB Solution; Nichirei).

\section{Preparation of yolk glanules}

Yolk granules were isolated from mature oocytes of diapause egg-producers and nondiapause egg-producers, and also from diapause eggs and nondiapause eggs at 12,36 and $72 \mathrm{hr}$ after oviposition. Mature oocytes and 12-hr eggs were dissected in $25 \mathrm{mM}$ Hepes- $\mathrm{NaOH}$ buffer, $\mathrm{pH}$ 7.5, containing $200 \mathrm{mM} \mathrm{NaCl}, 50 \mathrm{mM} \mathrm{KCl}$, $1 \mathrm{mM}$ DTT, $0.5 \mathrm{mM}$ PMSF, $10 \mu \mathrm{M}$ pepstatin A and $10 \mu \mathrm{M}$ leupeptin (buffer $\mathrm{C}$ ), and their chorions were removed. The yolk granule suspension thus obtained was homogenized very gently by hand using a glass-teflone homogenizer, and centrifuged at $100 \mathrm{~g}$ for $5 \mathrm{~min}$. The resulting pellet was washed twice with buffer $\mathrm{C}$. The final pellet was used as a yolk granule fraction. Since yolk granules have been located in the yolk cells from about $24 \mathrm{hr}$ after oviposition, the yolk cells were isolated from 36- and 72-hr eggs in Grace's medium, and collected by centrifugation at $100 \mathrm{~g}$ for $5 \mathrm{~min}$. The yolk cell fraction 
was suspended in buffer $\mathrm{C}$, homogenized very gently and centrifuged at $100 \mathrm{~g}$ for $5 \mathrm{~min}$. The resulting pellet was washed twice with buffer $\mathrm{C}$. The final pellet was used as a yolk granule fraction.

Incubation of the Vn-ecdysteroid-phosphate complex and yolk granules under acidic conditions

A partially purified $\mathrm{Vn}$-ecdysteroid-phosphate complex, containing $5.5 \mathrm{ng}$ of ecdysteroid-phosphates, was incubated with $100 \mathrm{mM}$ citrate buffer ( $\mathrm{pH} 4.5$ or $\mathrm{pH} 5.5)$, or with $100 \mathrm{mM}$ Tris-HCl buffer $(\mathrm{pH}$ 7.5 ), at $25^{\circ} \mathrm{C}$ for $30 \mathrm{~min}$, both of which contained $200 \mathrm{mM} \mathrm{NaCl}, 50$ $\mathrm{mM} \mathrm{KCl}, 1 \mathrm{mM}$ DTT, $2.5 \mathrm{mM}$ EDTA, $0.5 \mathrm{mM}$ PMSF, $10 \mu \mathrm{M}$ pepstatin A, $10 \mu \mathrm{M}$ leupeptin and $50 \mu \mathrm{M}$ cysteine protease inhibitor $N-\{N-(1,3-$ trans-carboxyoxiran-2-carbonyl)-L-leucyl\}-agmatine (E-64; Peptide Institute, INC., Japan). After incubation, $\mathrm{pH}$ of the mixture was readjusted to 7.5, the optimal $\mathrm{pH}$ for EPPase activity, and $6.25 \mathrm{ng}$ of recombinant EPPase (Yamada and Sonobe, 2003) was added to it. The mixture was incubated at $37^{\circ} \mathrm{C}$ for $60 \mathrm{~min}$. Amounts of free ecdysteroids liberated from ecdysteroid-phosphates by EPPase were quantified by RIA. After incubation at various $\mathrm{pHs}$, proteins in the reaction mixture were subjected to SDS-PAGE and analyzed by Western blotting using anti- $\mathrm{V} n$ antibody as described above.

The internal $\mathrm{pH}$ of yolk granules prepared from mature oocytes was equilibrated to various $\mathrm{pHs}$ using $10 \mu \mathrm{M}$ proton ionophores monensin (Sigma, USA) and nigericin (Wako, Japan). Yolk granules were incubated with $50 \mathrm{mM}$ citrate buffer $(\mathrm{pH} 4.5$ or $\mathrm{pH} 5.5)$, or with $50 \mathrm{mM}$ Tris- $\mathrm{HCl}$ buffer $(\mathrm{pH} 7.5)$, at $25^{\circ} \mathrm{C}$ for $30 \mathrm{~min}$, both of which contained $200 \mathrm{mM} \mathrm{NaCl}, 50 \mathrm{mM} \mathrm{KCl}, 1 \mathrm{mM}$ DTT, $2.5 \mathrm{mM}$ EDTA, $0.5 \mathrm{mM}$ PMSF, $10 \mu \mathrm{M}$ pepstatin A, $10 \mu \mathrm{M}$ leupeptin, $50 \mu \mathrm{M}$ membrane permeable E-64-d (Peptide Institute, INC.) and $10 \mu \mathrm{M}$ ionophores. After incubation, yolk granules were collected by centrifugation at $100 \mathrm{~g}$ for $5 \mathrm{~min}$. Ecdysteroid-phosphates were extracted with $80 \%$ methanol from yolk granules and the supernatant. Amounts of ecdysteroid-phosphates were quantified as described above. Proteins in yolk granules incubated at various $\mathrm{pHs}$ were subjected to Western blot analysis using anti- $V n$ antibody as described above.

\section{Percoll density gradient centrifugation of yolk granules}

Self-generated Percoll density gradient was prepared basically according to the method of Fagotto et al. (1991): $90 \%$ (1 ml), $60 \%$ (3 ml), 30\% (3 ml), and $2 \%(2 \mathrm{ml})$ of Percoll (Amersham Bioscience) were prepared with buffer $\mathrm{C}$, and individual solutions were layered in a $10 \mathrm{ml}$ centrifuge tube. The tube was centrifuged at $15,000 \mathrm{~g}$ for $15 \mathrm{~min}$. The yolk granule suspension $(1 \mathrm{ml}$ ) prepared from $0.15 \mathrm{~g}$ of mature oocytes or eggs was layered on the top of the gradient, and then the tube was centrifuged at $100 \mathrm{~g}$ for $30 \mathrm{~min}$. Fractions $(250 \mu \mathrm{l} /$ tube) were collected from the bottom of the tube. To remove Percoll, each fraction was diluted with two volumes of buffer $C$, and yolk granules were collected by centrifugation at $250 \mathrm{~g}$ for $10 \mathrm{~min}$. An aliquot of the yolk granule fraction was sonicated, and protein content was estimated spectrophotometrically at $A_{280}$. All procedures were carried out at $25^{\circ} \mathrm{C}$.

\section{Qualitative and quantitative analysis of internal pH of yolk gran-} ules

In order to observe acidification of yolk granules, yolk granules were subjected to acridine orange staining. Acridine orange (Sigma) is a fluorescent weak base commonly used to visualize acidic organelles: it fluoresces a green color at neutral $\mathrm{pH}$, but its fluorescence shifts from green to red when the dye is accumulated in acidic organelles (Azzone et al., 1984). Yolk granules were suspended in buffer $\mathrm{C}$ and exposed to $100 \mu \mathrm{M}$ acridine orange at $25^{\circ} \mathrm{C}$ for $30 \mathrm{~min}$. After incubation, the suspension was observed immediately under a fluorescence microscope (IX-FLA; Olympus, Japan) using BV excitation (400-440 nm).

For measurements of internal $\mathrm{pHs}$ of yolk granules, Oregon green 488 (Molecular Probes, USA), a fluorescent dye sensitive to acidic $\mathrm{pH}$, was used. Yolk granules were exposed to $12.5 \mu \mathrm{M}$ Oregon green 488 at $25^{\circ} \mathrm{C}$ for $30 \mathrm{~min}$. After incubation, they were observed immediately by confocal microscopy using the $488 \mathrm{~nm}$ line of an argon laser to excite Oregon green 488. To obtain a pH calibration curve, the internal $\mathrm{pH}$ of yolk granules was equilibrated to $\mathrm{pH} 5.0,5.25,5.5,5.75$ and 6.0 using proton ionophores monensin and nigericin. Yolk granules were incubated with $25 \mathrm{mM}$ MES buffer, $\mathrm{pH}$ from 5.0 to 6.0 , containing $200 \mathrm{mM} \mathrm{NaCl}, 50 \mathrm{mM} \mathrm{KCl}$ and $10 \mu \mathrm{M}$ ionophores at $25^{\circ} \mathrm{C}$ for $30 \mathrm{~min}$ and stained with Oregon green 488. In order to measure the internal $\mathrm{pH}$ of yolk granules, yolk granules from diapause eggs and nondiapause eggs were incubated with buffer $\mathrm{C}$ without ionophores and then stained with Oregon green 488. Fluorescent intensities in individual yolk granules in $100 \mu \mathrm{m}$ square, in which approximately 100 yolk granules were contained, were measured by confocal laser microscopy, and the mean intensity of the area was calculated.

\section{Western blot analysis of V-ATPase}

Yolk granules obtained by Percoll density gradient centrifugation were suspended in buffer $\mathrm{C}$, sonicated, and the lysate was centrifuged at $10,000 \mathrm{~g}$ for $20 \mathrm{~min}$. The supernatant was further centrifuged at $100,000 \mathrm{~g}$ for $40 \mathrm{~min}$. The final pellet was suspended in buffer $\mathrm{C}$ and used as a membrane fraction. The membrane fraction was solubilized with an equal volume of $100 \mathrm{mM}$ Tris- $\mathrm{HCl}$ buffer, $\mathrm{pH}$ 6.8 , containing $10 \%$ SDS, $10 \%$ 2-mercaptoethanol and $20 \%$ glycerol. The mixture was subjected to SDS-PAGE $(7.5 \% \mathrm{gel})$, and transferred to a polyvinylidene difluoride membrane (PVDF membrane; ATTO, Japan). The PVDF membrane was preincubated in Tris- $\mathrm{HCl}$ buffered saline, $\mathrm{pH} 7.5$, containing $5 \% \mathrm{BSA}$ at $25^{\circ} \mathrm{C}$ for 30 min and then incubated with anti-bovine vacuolar-type proton-translocating ATPase (V-ATPase) A subunit antibody, raised against a synthetic peptide corresponding with the amino acid sequence of $M$. sexta mid-gut V-ATPase A subunit (Graf et al., 1992), (1:200 dilution; Wako) at $4^{\circ} \mathrm{C}$ for $16 \mathrm{hr}$. Bound antibodies were detected with goat anti-rabbit peroxidase-conjugated IgG (1:5000 dilution; Wako), and the peroxidase activity was visualized using ECL Western Blotting Detention Reagents (Amersham Bioscience).

\section{RESULTS}

\section{Identification of ecdysteroid-phosphate binding-protein}

Conjugated ecdysteroids in mature oocytes of $B$. mori have been demonstrated to be phosphoric esters (Ohnishi et al., 1989; Kamba et al., 1994, Mamiya et al., 1995). In order to know whether or not ecdysteroid-phosphates in mature oocytes form complexes with some macromolecules, such as proteins, extractability of ecdysteroids by buffer A was examined. When ecdysteroids in mature oocytes were extracted with $80 \%$ methanol, about $80 \%$ of ecdysteroids were identified as ecdysteroid-phosphates (Table 1A). When ecdysteroids in mature oocytes were extracted with buffer A, about $90 \%$ of ecdysteroids (80\% methanol extract) were found in the $150,000 \mathrm{~g}$ supernatant and $80 \%$ of them were ecdysteroid-phosphates (Table $1 \mathrm{~A}$ ). These results suggest that ecdysteroids can be extracted efficiently with buffer $A$ as well as methanol. In order to analyze components of the $150,000 \mathrm{~g}$ supernatant, the supernatant was divided into two groups, high molecular fraction (fraction above approximately M.W. 5,000) and low molecular fraction (fraction below approximately M.W. 5,000) using a gel filtration column packed with Sephadex G-25 (1.6×15 $\mathrm{cm}$; Amersham Bioscience). Ecdysteroids in each fraction 
Table 1. Extractability of ecdysteroids in mature oocytes.

(A)

\begin{tabular}{lccc}
\hline \multicolumn{1}{c}{ Fraction } & $\begin{array}{c}\text { Ecdysteroid-phosphates } \\
(\mu \mathrm{g} / \mathrm{g} \text { ovaries })\end{array}$ & $\begin{array}{c}\text { Free ecdysteroids } \\
(\mu \mathrm{g} / \mathrm{g} \text { ovaries })\end{array}$ & $\begin{array}{c}\text { Total ecdysteroids } \\
(\mu \mathrm{g} / \mathrm{g} \text { ovaries })\end{array}$ \\
\hline MeOH extract & $2.97 \pm 0.11(79.8 \%)$ & $0.75 \pm 0.04(20.1 \%)$ & $3.72 \pm 0.16(100 \%)$ \\
\hline $\begin{array}{l}\text { Buffer extract } \\
(150,000 \mathrm{~g} \text { Sup })\end{array}$ & $2.68 \pm 0.09(80.0 \%)$ & $0.67 \pm 0.02(20.0 \%)$ & $3.35 \pm 0.09(100 \%)$ \\
\hline
\end{tabular}

(B)

\begin{tabular}{lcc}
\hline Fraction & $\begin{array}{c}\text { High molecular fraction } \\
(\mu \mathrm{g} / \mathrm{g} \text { ovaries })\end{array}$ & $\begin{array}{c}\text { Low molecular fraction } \\
(\mu \mathrm{g} / \mathrm{g} \text { ovaries })\end{array}$ \\
\hline $\begin{array}{l}\text { Buffer extract } \\
(150,000 \mathrm{~g} \text { Sup })\end{array}$ & $2.28 \pm 0.19(85.1 \%)$ & $0.32 \pm 0.06(11.9 \%)$ \\
\hline
\end{tabular}

(A) Ecdysteroids were extracted with $80 \%$ methanol or buffer $A$, and separated into two fractions, free ecdysteroids and ecdysteroid-phosphates by the silicic acid column. (B) The $150,000 \mathrm{~g}$ supernatant was applied to the gel filtration column to separate into low molecular fraction (below M.W. 5,000) and high molecular fraction (above M.W. 5,000). Ecdysteroids in each fraction were extracted with $80 \%$ methanol and quantified by RIA. The values represent means \pm SE of four separate experiments.
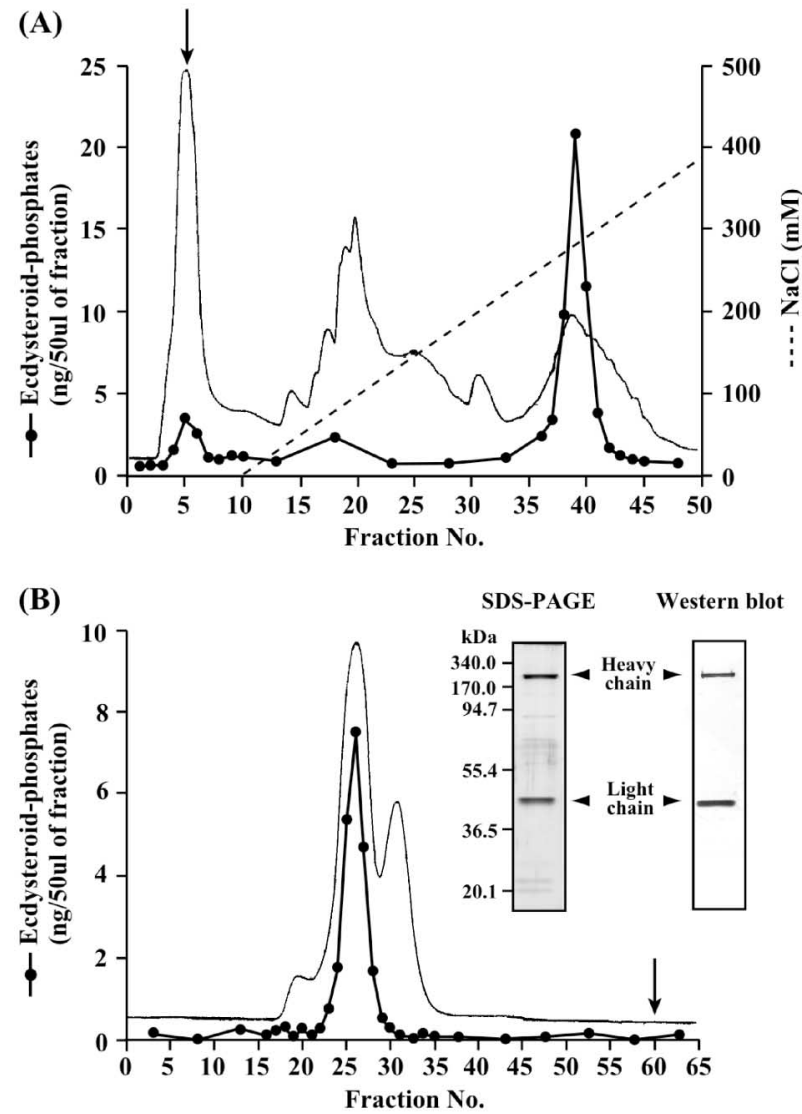

Fig. 1. Identification of ecdysteroid-phosphate binding-macromolecule. (A) Anion-exchange chromatography on a $Q$ Sepharose HP column. (B) Gel filtration chromatography on a Superdex $200 \mathrm{pg}$ column. The effluent was monitored at $280 \mathrm{~nm}$ (solid lines). Arrows indicate the elution position of marker free ecdysteroid-phosphates. The insets in (B) show SDS-PAGE analysis and Western blot analysis using anti- $\mathrm{Vn}$ antibody for RIA-positive fractions in the Superdex $200 \mathrm{pg}$ column chromatography. On SDS-PAGE analysis, proteins were visualized by silver staining. Arrowheads indicate the positions of the heavy and light chains of $\mathrm{Vn}$. The positions of the protein markers are indicated on the left of SDS-PAGE. were extracted with $80 \%$ methanol and quantified by RIA. About $85 \%$ of ecdysteroid-phosphates were detected in the high molecular fraction (Table 1B), despite that the M.W. of ecdysteroid-phosphates is about 540 .

Next, in order to identify the ecdysteroid-phosphate binding-molecule, the $150,000 \mathrm{~g}$ supernatant was applied to a Q Sepharose HP column. As shown in Fig. 1A, most of ecdysteroid-phosphates were detected in fractions 37-41 which were eluted in the concentration range from 250 to $300 \mathrm{mM} \mathrm{NaCl}$, although marker free ecdysteroid-phosphates were eluted as a single peak in fractions $4-6$. These results indicate that the binding-molecule exists in fractions 37-41. These fractions were pooled, and loaded on a Superdex $200 \mathrm{pg}$ column, and ecdysteroid-phosphates were eluted along with the macromolecule of $440 \mathrm{kDa}$ molecular mass (fraction Nos. 25-27) (Fig 1B). The fractions were pooled and analyzed by SDS-PAGE. As shown in Fig. 1B (inset), two major bands with approximately $180 \mathrm{kDa}$ and 44 $\mathrm{kDa}$ molecular mass were detected. Furthermore, Western blot analysis using anti- $\mathrm{Vn}$ antibody indicated that these bands corresponded with the two subunits of $\mathrm{Vn}$, heavy chain $(180 \mathrm{kDa})$ and light chain $(44 \mathrm{kDa})$ (Fig. 1B inset) as previously reported by Izumi et al. (1980). The similar results were obtained in mature oocytes from both diapause eggproducers and nondiapause egg-producers. Our present data suggest that most of ecdysteroid-phosphates are bound to $\mathrm{Vn}$ in mature oocytes of $B$. mori. This suggestion is consistent with the previous study showing that conjugated ecdysteroids are bound to $\mathrm{Vn}$ in L. migratoria (Lagueux et al., 1981).

\section{Localization of Vn-ecdysteroid-phosphate complex and EPPase}

Fig. 2 shows immunolocalization of EPPase and $V n$ in 72-hr nondiapause eggs. EPPase was localized mainly in the cytosol around the nucleus of yolk cells (Fig. 2A) which are formed about $24 \mathrm{hr}$ after oviposition (Takesue et al., 

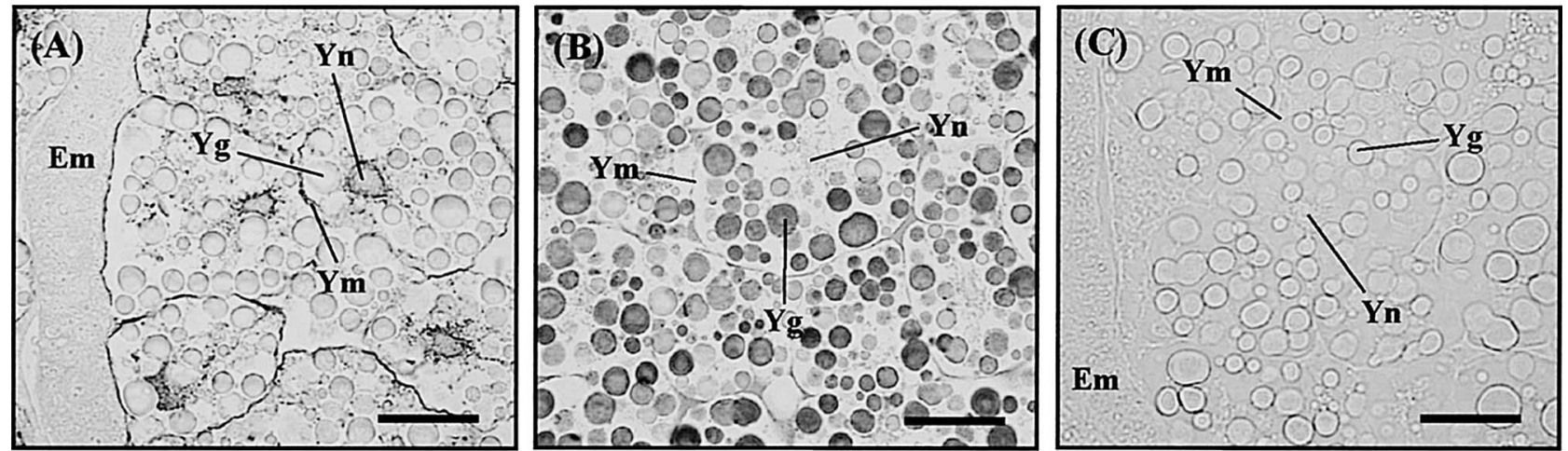

Fig. 2. Immunolocalization of EPPase and Vn. Paraffin sections of 72-hr nondiapause eggs were treated with anti-recombinant EPPase antibody (A), anti-Vn antibody (B), and non-immunized serum (C). Em, embryo; Yg, yolk granule; Ym, yolk cell membrane, Yn, yolk cell nucleus. Bars indicate $40 \mu \mathrm{m}$.

1976). However, the enzyme was not observed in yolk granules and also in embryonic cells (Fig. 2A). Fig. 2B shows that $\mathrm{Vn}$ is localized in yolk granules, each of which contained different amounts of $\mathrm{Vn}$. As expected, the sections treated with unimmunized serum showed no specific staining both in the cytosol and yolk granules (Fig. 2C). Since ecdysteroid-phosphates were found to be bound with $\mathrm{Vn}$, as mentioned in the previous section, these results suggest that the Vn-ecdysteroid-phosphate complex is located in yolk granules, and also indicate that the Vn-ecdysteroidphosphate complex is spatially separated from EPPase in yolk cells.

\section{Dephosphorylation of Vn-ecdysteroid-phosphate com- plex by EPPase}

In order to know the physiological significance of the $\mathrm{Vn}$-ecdysteroid-phosphate complex in yolk cells, the partially purified Vn-ecdysteroid-phosphate complex (see Fig. 1), containing $5.5 \mathrm{ng}$ of ecdysteroid-phosphates, was dissolved in $50 \mu \mathrm{l}$ of $100 \mathrm{mM}$ Tris-HCl buffer, $\mathrm{pH} 7.5$, and incubated with $6.25 \mathrm{ng}$ of the recombinant EPPase (Yamada and Sonobe, 2003) at $37^{\circ} \mathrm{C}$ for $120 \mathrm{~min}$. As shown in Fig. 3, Vnbound ecdysteroid-phosphates were scarcely hydrolyzed by EPPase, whereas ecdysteroid-phosphates that have been dissociated from $\mathrm{Vn}$ were completely hydrolyzed. These results suggest that the dephosphorylation of ecdysteroidphosphates by EPPase is prevented by $\mathrm{Vn}$. Therefore, the dissociation of ecdysteroid-phosphates from the Vn-ecdysteroid-phosphate complex and the subsequent release of ecdysteroid-phosphates from yolk granules seem to be prerequisite for EPPase to dephosphorylate ecdysteroid-phosphates in yolk cells.

\section{Release of ecdysteroid-phosphates from yolk granules}

To investigate the conditions under which ecdysteroidphosphates are dissociated from the Vn-ecdysteroid-phosphate complex, the partially purified Vn-ecdysteroid-phosphate complex was incubated at $\mathrm{pH} 7.5,5.5$ or 4.5 in the presence of protease inhibitors, and then the $\mathrm{pH}$ was readjusted to 7.5 , the optimal $\mathrm{pH}$ for EPPase activity, before

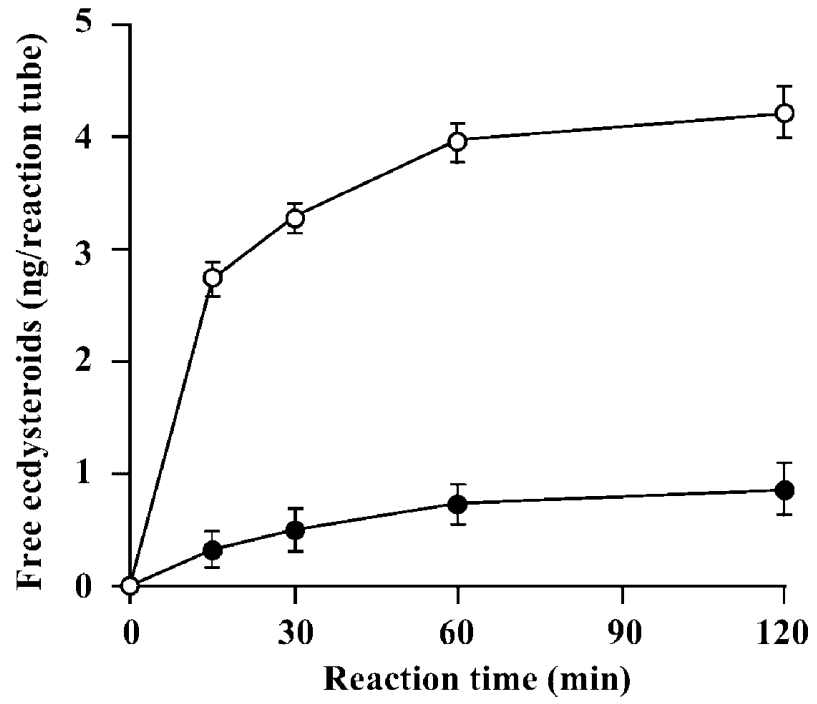

Fig. 3. Dephosphorylation of Vn-bound ecdysteroid-phosphates and free ecdysteroid-phosphates by EPPase. Vn-bound ecdysteroid-phosphates (closed circles) or free ecdysteroid-phosphates (open circles) were incubated with the recombinant EPPase (Yamada and Sonobe, 2003) for $120 \mathrm{~min}$. Aliquots were withdrawn at indicated intervals, and amounts of free ecdysteroids produced were measured by RIA. Each point represents mean \pm SE of three separate experiments.

the $\mathrm{Vn}$-ecdysteroid-phosphate complex was treated with EPPase (Fig. 4A). Ecdysteroid-phosphates were scarcely hydrolyzed by EPPase when the complex was preincubated at $\mathrm{pH}$ 7.5. By contrast, about $40 \%$ of ecdysteroid-phosphates were hydrolyzed when the complex was preincubated at $\mathrm{pH} 5.5$, and the percentage increased to about $90 \%$ when the complex was preincubated at $\mathrm{pH} 4.5$ (Fig. 4A). The result indicates that the acidic condition induces the dissociation of ecdysteroid-phosphates from the Vn-ecdysteroid-phosphate complex.

Next, to know more precisely the conditions that allow ecdysteroid-phosphates to be released from yolk granules, the internal $\mathrm{pH}$ of yolk granules prepared from mature oocytes was equilibrated to $\mathrm{pH} 7.5,5.5$ or 4.5 using proton 
(A)

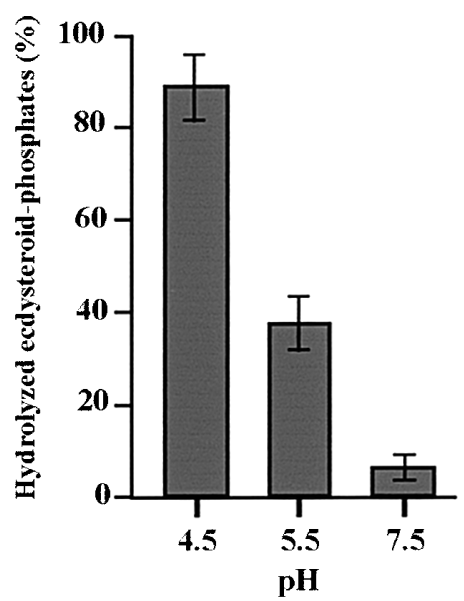

(B)

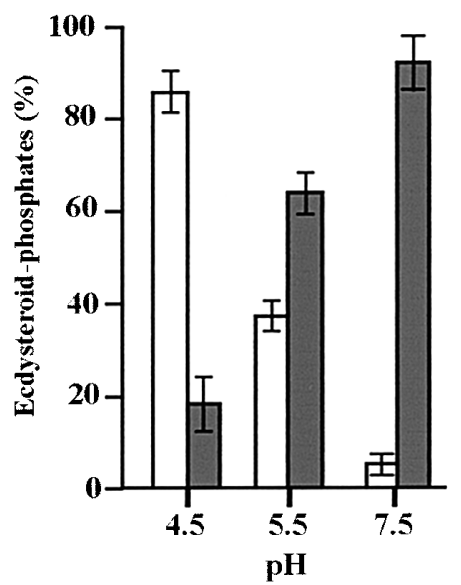

(C)

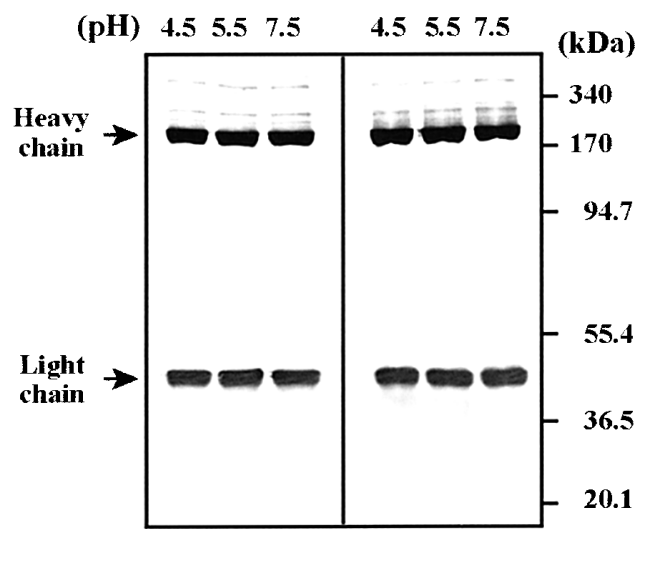

Fig. 4. Effects of various pHs on dissociation of ecdysteroid-phosphates from Vn-ecdysteroid-phosphate complex and release of ecdysteroidphosphates from yolk granules. (A) Dissociation of ecdysteroid-phosphates from the $\mathrm{Vn}$-ecdysteroid-phosphate complex. The $\mathrm{Vn}$-ecdysteroidphosphate complex was incubated at indicated $\mathrm{pHs}$ at $25^{\circ} \mathrm{C}$ for $30 \mathrm{~min}$ in the presence of protease inhibitors. Ecdysteroid-phosphates dissociated from the Vn-ecdysteroid-phosphate complex were hydrolyzed by EPPase, and resulting free ecdysteroids were quantified by RIA. The amount of ecdysteroid-phosphates extracted from the Vn-ecdysteroid-phosphate complex with $80 \%$ methanol was defined as $100 \%$. Each point represents mean \pm SE of three separate experiments. (B) Release of ecdysteroid-phosphates from yolk granules. Yolk granules were incubated at indicated $\mathrm{pHs}$ with monensin and nigericin at $25^{\circ} \mathrm{C}$ for $30 \mathrm{~min}$ in the presence of protease inhibitors. Yolk granules were precipitated by centrifugation at $100 \mathrm{~g}$, and amounts of ecdysteroid-phosphates in yolk granules and the supernatant were quantified by RIA. The amount of ecdysteroid-phosphates that were contained in freshly prepared yolk granules was expressed as $100 \%$. Open bars indicate the relative amounts of ecdysteroid-phosphates released from yolk granules, and solid bars indicate the relative amounts of ecdysteroid-phosphates remained in yolk granules. Each point represents mean \pm SE of three separate experiments. (C) Analysis of Vn by Western blot analysis using anti- $\mathrm{Vn}$ antibody. Left panel, the $\mathrm{Vn}$-ecdysteroid-phosphate complex incubated at various $\mathrm{pHs}$ (see (A)). Right panel, proteins extracted from yolk granules incubated at various $\mathrm{pHs}(\mathrm{see}(\mathrm{B}))$. The positions of the protein markers are indicated on the right.

ionophores monensin and nigericin in the presence of protease inhibitors (Fig. 4B). At pH 7.5, most of ecdysteroidphosphates remained in yolk granules. However, at $\mathrm{pH} 5.5$, about $40 \%$ and at $\mathrm{pH} 4.5$, more than $80 \%$ of ecdysteroidphosphates were released in the supernatant, i.e. outside of yolk granules (Fig. 4B).

To examine whether the degradation of $\mathrm{Vn}$ could occur when the $\mathrm{Vn}$-ecdysteroid-phosphate complex and yolk granules were treated with acidic media, Western blot analysis was carried out using anti- $\mathrm{Vn}$ antibody (Fig. 4C). As shown in Fig. $4 \mathrm{C}$, at every $\mathrm{pH}$ tested, electrophoretic mobilities of two subunits of $\mathrm{Vn}$, heavy and light chains, were unchanged and also additional bands reactive to anti- $V n$ antibody were not observed. This result indicates that $\mathrm{Vn}$ in the $\mathrm{Vn}$-ecdysteroid-phosphate complex (left panel) as well as $\mathrm{Vn}$ in yolk granules (right panel) are not degraded under the acidic condition. Taken together, our results indicate that ecdysteroid-phosphates are only dissociated from the Vn-ecdysteroid-phosphate complex to be released from yolk granules on the acidic condition without the degradation of $\mathrm{Vn}$.

\section{Acidification of yolk granules during early embryonic development}

In the African soft tick Ornithodoros moubata (Fagotto, 1991), the stick insect Carausius morosus (Fausto et al., 2001) and B. mori (Yamahama et al., 2003), it has been demonstrated that different types of yolk granules which dif- fer in their density and/or size are present. Yolk granules, prepared from mature oocytes, 12-, 36- and 72-hr diapause eggs and nondiapause eggs, were distributed in a Percoll density gradient (Fig. 5). Mature oocytes from diapause egg-producers and nondiapause egg-producers were found to contain a single population of yolk granules, tentatively named light yolk granules (LYGs) (Fig. 5A). Yolk granules taken from newly laid eggs also formed a single population of LYGs (data not shown). However, 12-hr eggs (cellular blastderm stage) contained another population of yolk granules in addition to LYGs, which appeared in the higher-density fraction, tentatively named dense yolk granules (DYGs) (Fig. 5B). Amounts of DYGs increased as embryonic development proceeded up to $36 \mathrm{hr}$ (early gustrula stage) (Fig. $5 \mathrm{C}$ ), whereas amounts of LYGs decreased (Fig. 5B-D). This change in the proportion between LYGs and DYGs suggests the possibility that some of LYGs are transformed to DYGs after oviposition. The patterns of distribution of yolk granules in the Percoll density gradient and their changes during development were similar both in diapause eggs and nondiapause eggs.

In order to observe the internal $\mathrm{pH}$ of yolk granules, yolk granules of LYG and DYG populations were separately stained with acridine orange. In mature oocytes from diapause egg-producers as well as those form nondiapause egg-producers, the $\mathrm{pH}$ of all LYGs was found to be nearly neutral (Fig. 5A). In nondiapause eggs, most LYGs 
(A)
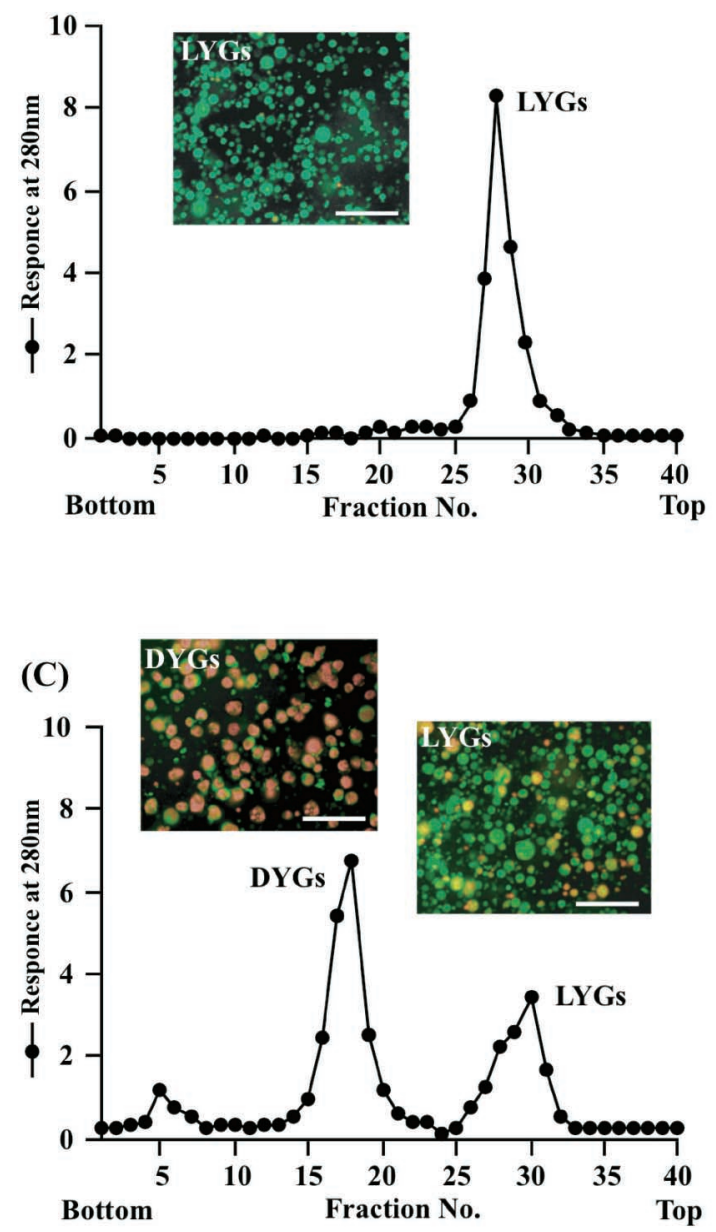

(B)

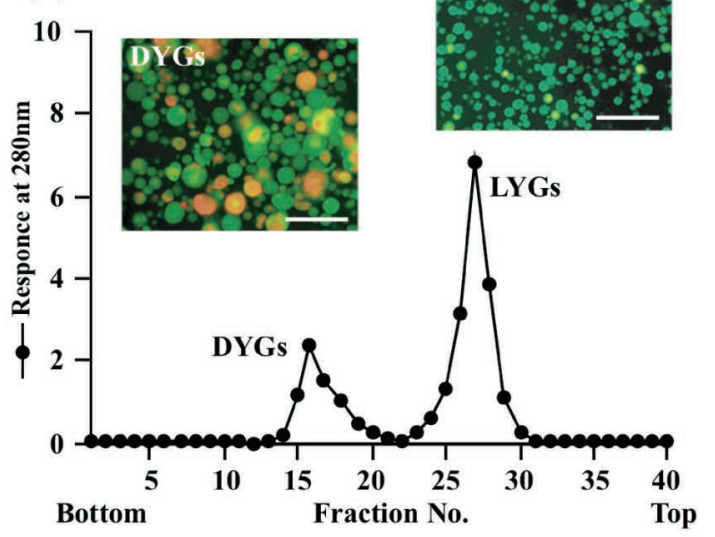

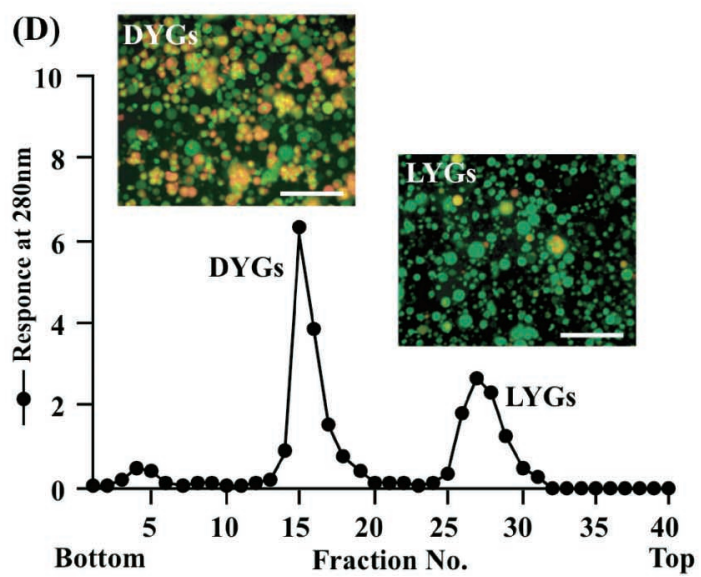

Fig. 5. Percoll density gradient patterns of yolk granules and acridine orange fluorescence of yolk granules. Yolk granules were prepared from mature oocytes of nondiapaus egg-producers, and nondiapause eggs at 12, 36 and $72 \mathrm{hr}$ after oviposition. Yolk granules obtained were distributed by Percoll density gradient centrifugation. Closed circles indicate protein content in yolk granules. (A) Mature oocytes from nondiapause egg-producers. (B) 12-hr eggs (cellular blastderm stage). (C) 36-hr eggs (gustrula stage). (D) 72-hr eggs (early organogenesis stage). The stages of embryogenesis in nondiapause eggs are based on our previous paper (Sonobe et al., 1986). Yolk granules were stained with acridine orange and observed by fluorescent microscopy. DYGs, dense yolk granules; LYGs, light yolk granules. Bars indicate $50 \mu \mathrm{m}$.
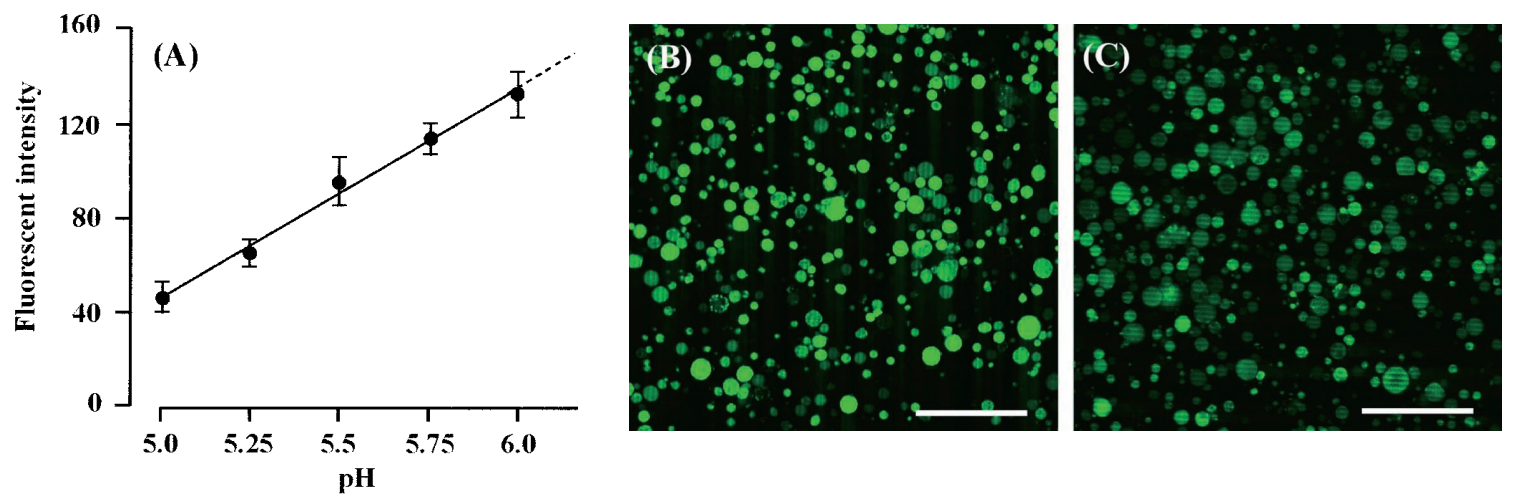

Fig. 6. Quantitative analysis of internal pH of DYGs. (A) The standard pH calibration curve, based on the changes in fluorescent intensity in DYGs exposed to Oregon green 488 at indicated pHs. DYGs prepared from 36-hr nondiapause eggs were incubated with $25 \mathrm{mM}$ MES buffer solution ( $\mathrm{pH}$ from 5.0 to 6.0) containing ionophores, monensin and nigericin, and then stained with Oregon green 488 . The fluorescent intensity in approximately 100 DYGs in $100 \mu \mathrm{m}$ square was measured by confocal microscopy using the $488 \mathrm{~nm}$ line of an argon laser to excite Oregon green 488. Each point represents mean \pm SE of three separate experiments. (B, C) DYGs in 36-hr diapause eggs (B) and 36-hr nondiapause eggs (C) were incubated with buffer $\mathrm{C}(\mathrm{pH} 7.5)$ without ionophores, monensin and nigericin, and then stained with Oregon green 488 . Bars indicate $50 \mu \mathrm{m}$. 
remained to be neutral throughout embryonic development (Fig. 5 B-D). However, some of DYGs began to be acidified from $12 \mathrm{hr}$ after oviposition (Fig. 5B), and almost all DYGs were acidified $36 \mathrm{hr}$ after oviposition (Fig. 5C). The percentage of acidified DYGs slightly decreased $72 \mathrm{hr}$ after oviposition (Fig. 5D). Although the internal $\mathrm{pH}$ of yolk granules could not accurately be measured by our acridine orange method, acridine orange fluorescence in DYGs of diapause eggs appears to be slightly lower than that in DYGs of nondiapause eggs (data not shown).

These observations were corroborated by quantitative analysis of the internal pH of DYGs with Oregon green 488. As seen in the standard $\mathrm{pH}$ calibration curve, the fluorescent intensity of Oregon green 488 was reduced as $\mathrm{pH}$ decreased (Fig. 6A). As shown in Fig. 6B, in DYGs of 36-hr diapause eggs, strong fluorescence (average intensity: $142.7 \pm 5.1$ ) was detected, indicating that the internal $\mathrm{pH}$ of DYGs is above 6.0. However, in DYGs of 36-hr nondiapause eggs, the weak fluorescence (average intensity: $67.9 \pm 3.6$ ) was detected, indicating that the internal $\mathrm{pH}$ is $5.2 \pm 0.1$ (Fig. 6A, C). This shows that the internal $\mathrm{pH}$ of DYGs in nondiapause eggs is clearly lower than that in diapause eggs.

In order to examine whether or not DYGs contain Vn, Western blot analysis was carried out using anti-Vn antibody (Fig. 7). In mature oocytes from nondiapause egg-producers, Vn was detected in the LYG fraction (Fig. 7), but no appreciable difference in the level of $\mathrm{Vn}$ was observed between mature oocytes from diapause egg-producers and those from nondiapause egg-producers (data not shown). After oviposition, the level of $V n$ in the $L Y G$ fraction decreased from 12 to $36 \mathrm{hr}$ after oviposition (Fig. 7). Conversely, the level of $\mathrm{Vn}$ in the DYG fraction increased during the period from 12 to $72 \mathrm{hr}$ after oviposition. Finally, $\mathrm{Vn}$ was found mainly in the DYG fraction from $36 \mathrm{hr}$ after oviposition (Fig. 7). According to Zhu and his colleagues (1986), the level of $\mathrm{Vn}$ in $B$. mori eggs remained almost unchanged from the early to middle stage of embryonic development. In addition, the profile of changing levels of $\mathrm{Vn}$ (Fig. 7) is similar to that of the change in the relative proportion of LYGs and

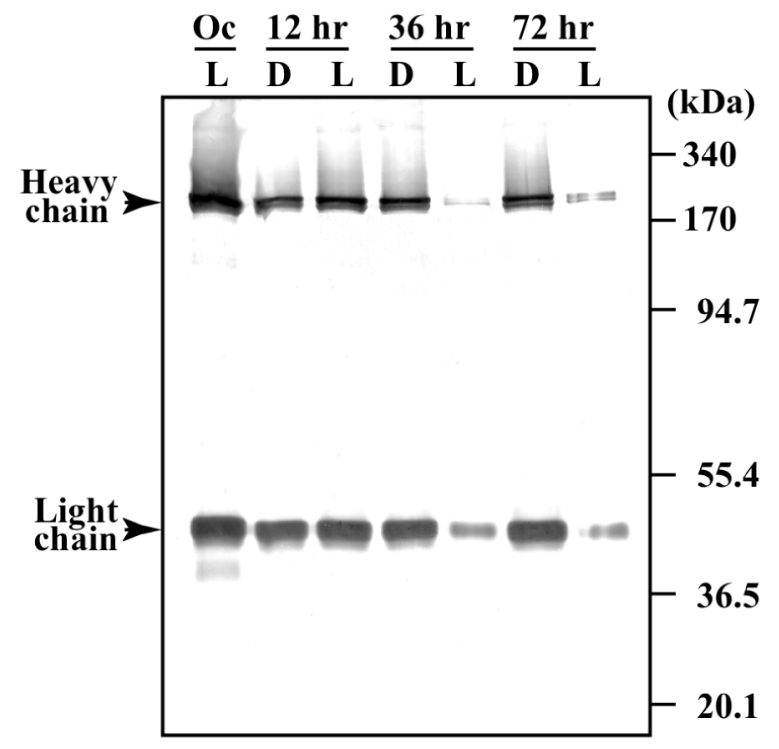

Fig. 7. Western blot analysis of $\mathrm{Vn}$ in yolk granules. LYGs and DYGs were prepared from mature oocytes of nondiapause egg-producers and 12-, 36- and 72-hr nondiapause eggs, and sonicated. Aliquots of each lysate were subjected to SDS-PAGE and analyzed by Western blotting using anti- $\mathrm{Vn}$ antibody. The positions of the protein markers are indicated on the right. Oc, mature oocytes; L, LYGs; D,DYGs.

DYGs (Fig. 5). These results suggest that LYGs containing $\mathrm{Vn}$ are transformed to DYGs during early embryonic development.

Taken together, our results indicate that DYGs in 1272-hr nondiapause eggs are exposed to stronger acidic condition (about $\mathrm{pH}$ 5.2) than those in 12-72-hr diapause eggs (above $\mathrm{pH}$ 6.0), and thereby ecdysteroid-phosphates in DYGs in nondiapause eggs are dissociated from the Vnecdysteroid-phosphate complex and released into the cytoplasm.

\section{Role of V-ATPase in acidification of yolk granules}

Recently, it was demonstrated in eggs of the blood-
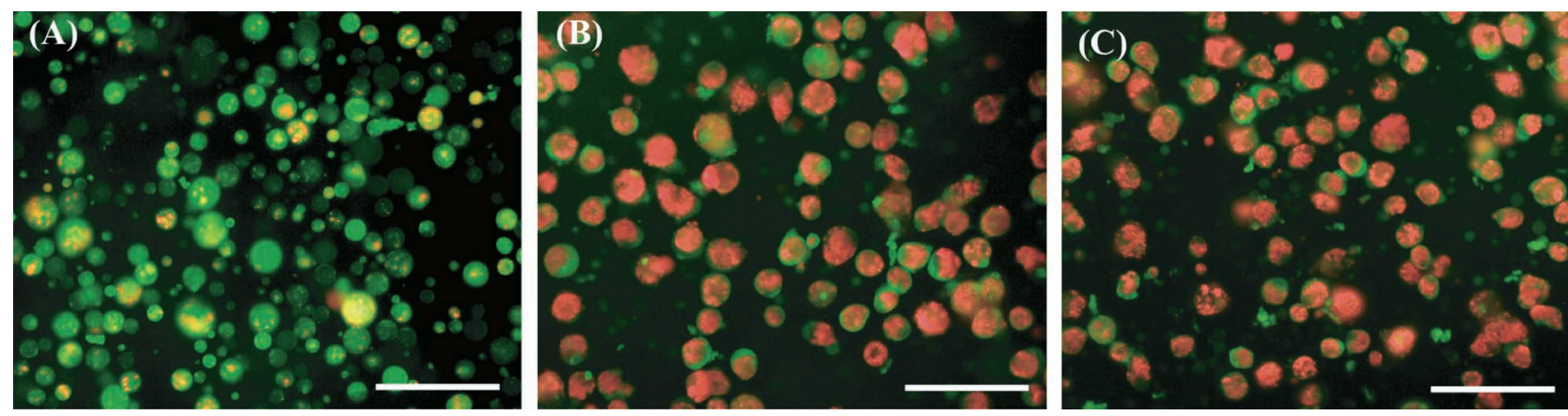

Fig. 8. Effect of bafilomycin $A_{1}$ and fluoride on acidification of DYGs. (A) DYGs in 36-hr nondiapause eggs were incubated with 1 mM ATP and $5 \mu \mathrm{M}$ bafilomycin $\mathrm{A}_{1}$ (specific inhibitor of $\mathrm{V}$-ATPase) in buffer C. (B) DYGs in 36-hr nondiapause eggs were incubated with $1 \mathrm{mM} \mathrm{MgCl}_{2}$, $0.3 \mathrm{mM}$ inorganic pyrophosphate and $10 \mathrm{mM}$ fluoride (strong inhibitor of $\mathrm{H}^{+}$-PPase) in buffer $\mathrm{B}$. (C) DYGs in 36-hr nondiapause eggs were incubated without bafilomycin $A_{1}$ and fluoride. After incubation at $25^{\circ} \mathrm{C}$ for $60 \mathrm{~min}$, DYGs were stained with acridine orange and observed under the fluorescent microscope. Bars indicate $50 \mu \mathrm{m}$. 


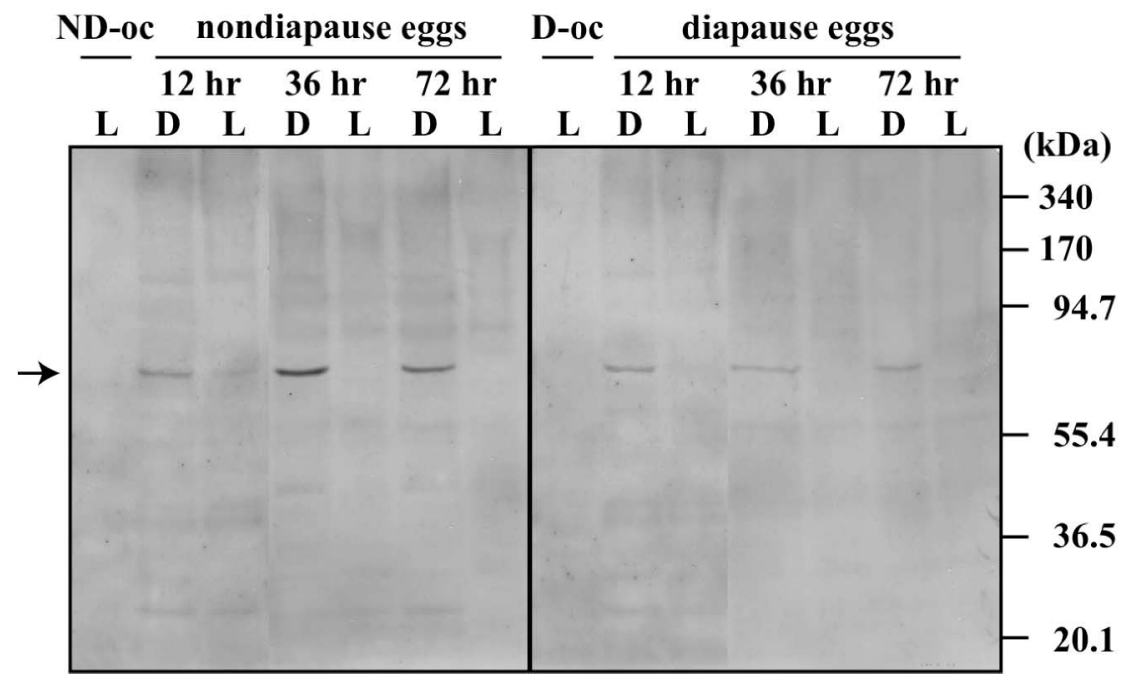

Fig. 9. Western blot analysis of V-ATPase in yolk granules. The membrane fraction of yolk granules was prepared from mature oocytes and eggs at various developmental stages. Twenty $\mu \mathrm{g}$ of proteins in the membrane fraction were subjected to SDS-PAGE and analyzed by Western blotting using anti-V-ATPase A subunit antibody. Arrow indicates signal band for V-ATPase A subunit. The positions of the protein markers are indicated on the right. ND-oc, mature oocytes from nondiapause egg-producers; D-oc, mature oocytes from diapause egg-producers; L, LYGs; D, DYGs.

sucking insect Rhodnius prolixus that the acidification of yolk granules is caused by two kinds of proton pumps, V-ATPase and proton pyrophosphatase $\left(\mathrm{H}^{+}\right.$-PPase) (Motta et al., 2004). To investigate whether these proton pumps are also involved in the acidification of yolk granules in $B$. mori, effects of bafilomycin $A_{1}$ (specific inhibitor of V-ATPase) and fluoride (strong inhibitor of $\mathrm{H}^{+}$-PPase) on the acidification of yolk granules were tested. When DYGs obtained from 36-hr nondiapause eggs were exposed to bafilomycin $A_{1}$, the acidification of DYGs was strongly inhibited (Fig. 8A). However, when DYGs were treated with fluoride, the acidification of DYGs was scarcely affected (Fig. 8B). DYGs treated without bafilomycin $A_{1}$ and fluoride showed similar acridine orange staining (Fig. $8 \mathrm{C}$ ). These results suggest that the acidification of DYGs is caused mainly by V-ATPase.

In order to determine quantitative changes in V-ATPase protein in yolk granules during early embryogenesis, the membrane fraction of yolk granules was analyzed by Western blotting using antibody against V-ATPase $V_{1}$ domain A subunit (Fig. 9). In mature oocytes, both from diapause eggproducers and nondiapause egg-producers, V-ATPase was not detected in LYGs. In nondiapause eggs, V-ATPase was not detected in LYGs throughout embryonic development, but a weak signal of V-ATPase was detected in DYGs from $12 \mathrm{hr}$ after oviposition, and it was most intensified $36 \mathrm{hr}$ after oviposition, and decreased slightly $72 \mathrm{hr}$ after oviposition. In diapause eggs, V-ATPase was not detected in LYGs, but a weak signal of V-ATPase was detected in DYGs (Fig. 9).

\section{Changes in the amount of free ecdysteroid-phosphates}

In order to investigate changes in the amount of free ecdysteroid-phosphates dissociated from the Vn-ecdysteroid-phosphate complex during embryonic development,

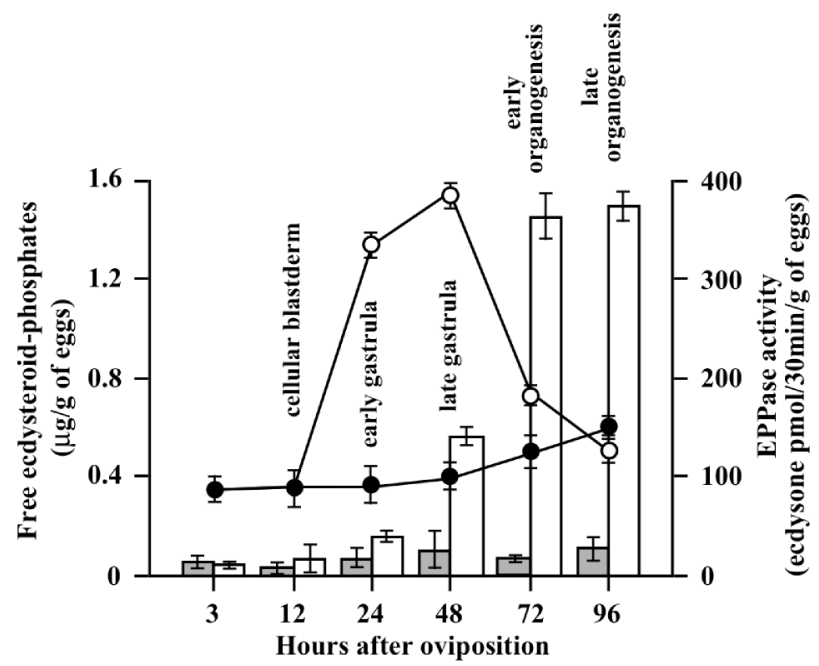

Fig. 10. Changes in the amounts of free ecdysteroid-phosphates and EPPase activity during early embryonic development. Closed circles and open circles indicate free ecdysteroid-phosphates in diapause eggs and nondiapause eggs, respectively. Solid bars and open bars indicate EPPase activities in diapause eggs and nondiapause eggs, respectively. The EPPase activity was determined as described in our previous papers (Yamada et al., 2002; Yamada and Sonobe, 2003). Results are expressed as mean \pm SE of three separate experiments. The stages of embryogenesis in nondiapause eggs are based on our previous paper (Sonobe et al., 1986). Diapause eggs cease to develop at the late gastrulation stage (Sonobe et al., 1986).

ecdysteroids were extracted with buffer B from eggs at various developmental stages, and free ecdysteroid-phosphates were separated from the $V n$-ecdysteroid-phosphate complex by $Q$ Sepharose column chromatography (see Fig. 1). The amount of free ecdysteroid-phosphates was quanti- 
fied by RIA. In nondiapause eggs, amounts of free ecdysteroid-phosphates increased from $12 \mathrm{hr}$ (cellular blastderm stage) to $48 \mathrm{hr}$ (late gastrula stage), and then decreased rapidly as embryonic development proceeded (Fig. 10). In contrast, in diapause eggs, amounts of free ecdysteroidphosphates always remained at low levels (Fig. 10). The EPPase activity in nondiapasue eggs increased slightly from $24 \mathrm{hr}$ after oviposition and reached a plateau at 72-96 hr after oviposition. However, in diapause eggs, it remained at low levels (Fig. 10). These facts suggest that EPPase is responsible for the decrease of the amount of free ecdysteroid-phosphates from $72 \mathrm{hr}$ to $96 \mathrm{hr}$ in nondiapause eggs.

\section{DISCUSSION}

In various insect species, it has been supposed that conjugated ecdysteroids are a storage form which supplies active free ecdysteroids during early embryonic development (Hoffmann and Lagueux, 1985; Hagedorn, 1985; Yamada and Sonobe, 2003; Sonobe and Yamada, 2004). In L. migratoria and D. melanogaster, conjugated ecdysteroids have been demonstrated to be bound to $\mathrm{Vn}$ or yolk proteins, and it was supposed that the degradation of these proteins leads to the release of conjugated ecdysteroids, resulting in an increase of free ecdysteroids (Lagueux et al., 1981, 1984; Bownes et al., 1988). Recently, the presence of EPPase, which catalyzes the dephosphorylation of ecdysteroid-phosphates to increase the amount of free ecdysteroids, has been demonstrated in $B$ mori eggs (Yamada and Sonobe, 2003).

In the present study, we demonstrated that (1) maternal ecdysteroid-phosphates are bound to $\mathrm{Vn}$ in $B$. mori eggs as well (Fig. 1), (2) the Vn-ecdysteroid-phosphate complex is stored in yolk granules (Fig. 2B), (3) EPPase is localized in the cytosol around the nucleus of yolk cells (Fig. 2A), but (4) when the Vn-ecdysteroid-phosphate complex is incubated with EPPase in vitro, free ecdysteroids are scarcely produced, although free ecdysteroid-phosphates are easily dephosphorylated by EPPase (Fig. 3). These results suggest that ecdysteroid-phosphates must be dissociated from the Vn-ecdysteroid-phosphate complex and released into the cytosol to be dephosphorylated by EPPase. We had first considered the possibility that the dissociation of ecdysteroid-phosphates from the Vn-ecdysteroid-phosphate complex is caused by the degradation of $\mathrm{Vn}$ as previously supposed in L. migratoria (Lagueux et al., 1981, 1984). However, Zhu and his colleagues (1986) showed that the level of $\mathrm{Vn}$ in $B$. mori eggs remain almost unchanged from the early to middle stage of embryonic development, but begin to decrease after the middle stage when larval differentiation proceeds. Thus, we have wondered how ecdysteroid-phosphates could dissociate from the Vn-ecdysteroid-phosphate complex during embryonic development from the early to middle stages when $\mathrm{Vn}$ still remained intact.

In the present study, it was clearly demonstrated that the dissociation of ecdysteroid-phosphates from the $\mathrm{Vn}$ - ecdysteroid-phosphate complex and their subsequent release from DYGs are induced by the acidification of DYGs (Fig. 4A, B, 5, 6, 10), but not by the Vn degradation (Fig. 4C, 7 ), and acidification of DYGs is induced by V-ATPase (Fig. 8, 9). In D. melanogaster (Bohrmann and Braun, 1999), C. morosus (Fausto et al., 2001) and the southern cattle tick Boophilus microplus (Abreu et al., 2004), V-ATPase has been demonstrated to be involved in the acidification of yolk granules. Recently, in $R$. prolixus (Motta et al., 2004), it was shown that V-ATPase and $\mathrm{H}^{+}$-PPase, which co-exist in the yolk granule membrane, cooperatively promote the acidification of yolk granules. However, our results in B. mori suggest that the acidification of DYGs is regulated mainly by $\mathrm{V}$ ATPase localized in the yolk granule membrane (Fig. 8, 9). Therefore, it is conceivable that the regulation of V-ATPase activity is a key process for the release of ecdysteroid-phosphates from DYGs during early embryonic development.

It has been well established that $\mathrm{Vn}$ of insects, containing lipids, carbohydrates and metals, is stored in oocytes and consumed as the source of nutrients during embryonic development (Yamashita and Indrasith, 1988; Raikhel and Dhadialla, 1992; Niimi et al., 1993). In the present study, we showed that $\mathrm{Vn}$ functions as not only the nutritional source, but also as the reservoir of maternal ovarian ecdysteroidphosphates during early embryonic development, and revealed the biochemical mechanism by which Vn-bound ecdysteroid-phosphates exert their function on early embryonic development. The fact that ecdysteroid-phosphates are dissociated from the Vn-ecdysteroid-phosphate complex on the acidic condition may imply that ecdysteroid-phosphates are bound to $\mathrm{Vn}$ with ionic bonds. However, further experiments are necessary to understand biochemical characteristics of the Vn-ecdysteroid-phosphates complex, such as the number of binding sites and the binding specificity.

Taken together, mechanisms which control the release of ecdysteroid-phosphates from yolk granules and their dephosphorylation during embryonic development may be summarized as follows: (1) In mature oocytes, phosphoric esters of active hormone $20 \mathrm{E}$ and its precursors such as 2deoxyecdysone, ecdysone and 2-deoxy-20-hydroxyecdysone (Watanabe and Ohnishi, 1984; Ohnishi, 1986; Ohnishi et al., 1989) form a complex with $\mathrm{Vn}$, and the complex is stored in LYGs. (2) Some of LYGs are transformed to DYGs after the cellular blastoderm stage, and in the latter, the acidification is induced by V-ATPase. (3) The acidification of DYGs causes the dissociation of ecdysteroid-phosphates from the Vn-ecdysteroid-phosphate complex, and dissociated ecdysteroid-phosphates are released into the cytosol of yolk cells. (4) The released ecdysteroid-phosphates are dephosphorylated by EPPase that has been synthesized de novo in yolk cells between the gastrula stage and the organogenesis stage (Yamada and Sonobe, 2003). (5) 20E is produced not only by the dephosphorylation of 20-hydroxyecdysone 22-phosphate, but also by hydroxylation of precursors of $20 \mathrm{E}$ that have been produced by their dephosphorylation (Sonobe et al., 1999; Horike and Sonobe, 1999; 
Horike et al., 2000; Sonobe and Yamada, 2004). The abovementioned mechanism is of crucial importance for embryonic development of $B$. mori, in view of the fact that $20 \mathrm{E}$ plays indispensable roles in embryonic development of $B$. mori by exerting its function via the ecdysteroid receptor BmEcR-B1/BmUSP (Makka et al., 2002).

In nondiapause eggs, activation of the above-mentioned mechanisms increases 20E level (Sonobe et al., 1997; Horike and Sonobe, 1999; Yamada and Sonobe, 2003). However, in diapause eggs, V-ATPase A subunit levels remained low throughout early embryonic development (Fig. 9 right panel), thus the internal pH of DYGs is kept at higher levels in diapause eggs than that in nondiapause eggs. Consequently, ecdysteroid-phosphates are hardly released from DYGs during early embryonic development in diapause eggs (Fig. 10). Furthermore, in diapause eggs, EPPase activity remains at low levels (Fig. 10 in this paper; Yamada and Sonobe, 2003), and therefore 20E in diapause eggs is kept at low levels (Sonobe et al., 1997; Yamada and Sonobe, 2003). These differences found between diapause eggs and nondiapause eggs in the control mechanisms underlying $20 \mathrm{E}$ production in yolk cells may explain their different developmental fates.

\section{ACKNOWLEDGEMENTS}

The antiserum to $B$. mori $V n$ was a gift of Professor Susumu Izumi of Tokyo Metropolitan University. We thank Mr. Kohei Atuta of Konan University for his technical assistance on immunohistochemistry. We wish to express our gratitude to Dr. Eiji Ohnishi of Nagoya University for many helpful suggestions. We also thank Professor Emeritus Yoshio Masui of University of Toronto and Konan University for critical reading of the manuscript. This work was supported in part by Grants-in-Aid from the Japan Society for the Promotion of Science (11640671), and from MEXT ORC (20042008), Japan, and by funds from the Hirao Taro Foundation of the Konan University Association for Academic Research.

\section{REFERENCES}

Abreu LA, Valle D, Manso PP, Façanha AR, Pelajo-Machado M, Masuda H, Masuda A, Vaz Jr I, Lenzi H, Oliveira PL, Logullo C (2004) Proteolytic activity of Boophilus microplus yolk procathepsin $\mathrm{D}(\mathrm{BYC})$ is coincident with cortical acidification during embryogenesis. Insect Biochem Mol Biol 34: 443-449

Azzone GF, Pietrobon D, Zoratti M (1984) Determination of the proton electrochemical gradient across biological membrane. In "Current Topics in Bioenergetics" Ed by CP Lee, Academic press, Orlando, pp 1-77

Bohrmann J, Braun B (1999) Na,K-ATPase and V-ATPase in ovarian follicles of Drosophila melanogaster. Biol Cell 91: 85-98

Bownes M, Shirras A, Blair M, Collins J, Coulson A (1988) Evidence that insect embryogenesis is regulated by ecdysteroids released from yolk proteins. Proc Natl Acad Sci USA 85: 15541557

Bullière D, Bullière F, De Reggi M (1979) Ecdysteroid titers during ovarian and embryonic development in Blaberus craniifer. Roux's Arch Dev Biol 186: 103-114

Fagotto F (1991) Yolk degradation in tick eggs: III. Developmentally regulated acidification of the yolk spheres. Dev Growth Differ 33: $57-66$
Fausto AM, Gambellini G, Mazzini M, Cecchettini A, Masetti M, Giorgi $F$ (2001) Yolk granules are differentially acidified during embryo development in the stick insect Carausius morosus. Cell Tissue Res 305: 433-443

Fukuda $S$ (1951) The production of the diapause eggs by transplanting the suboesophageal ganglion in the silkworm. Proc Jpn Acad 27: 672-677

Gilbert LI (2004) Halloween genes encode P450 enzymes that mediate steroid hormone biosynthesis in Drosophila melanogaster. Mol Cell Endocrinol 215: 1-10

Graf R, Novak FJ, Harvey WR, Wieczorek H (1992) Cloning and sequencing of CDNA encoding the putative insect plasma membrane V-ATPase subunit A. FEBS Lett 300: 119-122

Hagedorn HH (1985) The role of ecdysteroids in reproduction. In "Comprehensive Insect Physiolgy, Biochemistry, and Pharmacology, Vol. 8", Ed by GA Kerkut, LI Gilbert, Pergamon, Oxford, pp 205-262

Hoffmann JA, Lagueux M (1985) Endcrine aspects of embryonic development in insects. In "Comprehensive Insect Physiolgy, Biochemistry, and Pharmacology, Vol. 1", Ed by GA Kerkut, LI Gilbert, Pergamon, Oxford, pp 435-460

Horike N, Sonobe H (1999) Ecdysone 20-monooxygenase in eggs of the silkworm, Bombyx mori: enzymatic properties and developmental changes. Arch Insect Biochem Physiol 41: 9-17

Horike N, Takemori H, Nonaka Y, Sonobe H, Okamoto M (2000) Molecular cloning of NADPH-cytochrome P450 oxidoreductase from silkworm eggs: its involvement in 20-hydroxyecdysone biosynthesis during embryonic development. Eur $\mathrm{J}$ Biochem 267: 6914-6920

Izumi S, Tomino S, Chino H (1980) Purification and molecular properties of vitellin from the silkworm, Bombyx mori. Insect Biochem 10: 199-208

Kamba M, Mamiya Y, Sonobe H, Fujimoto Y (1994) 22-Deoxy-20hydroxyecdysone and its phosphoric ester from ovaries of the silkworm, Bombyx mori. Insect Biochem Mol Biol 24: 395-402

Lafont R, Connt J-L, Delbecque J-P, Porcheron P, Dauphin-Villemant D, Garcia M (1995) Comparative studies on ecdysteroids. In "Recent Advances in Insect Biochemistry and Molecular Biology", Ed by E Ohnish, H Sonobe, YS Takahashi, Nagoya University Press, Nagoya, pp 45-91

Lagueux M, Harry P, Hoffmann JA (1981) Ecdysteroids are bound to vitellin in newly laid eggs of Locasta. Mol Cell Endocrinol 24: 325-338

Lagueux M, Hetru C, Goltzené F, Kapplar C, Hoffmann JA (1979) Ecdysone titer and metabolism in relations to cuticulogenesis in embryos of Locusta migratoria. J Insect Physiol 25: 709-723

Lagueux M, Hoffmann JA, Goltzené F, Kappler C, Tsoupras G, Hetru C, Luu B (1984) Ecdysteroids in ovaries and embryos of Locusta migratoria. In "Biosynthesis, Metabolism and Mode of Action of Invertebrate Hormones", Ed by JA Hoffmann, M Porchet, Springer-Verlag, Heidelberg, pp 168-180

Makka T, Seino A, Tomita S, Fujiwara H, Sonobe H (2002) A possible role of 20-hydroxyecdysone in embryonic development of the silkworm, Bombyx mori. Arch Insect Biochem Physiol 51: $111-120$

Makka T, Sonobe H (2000) Ecdysone metabolism in diapause eggs and non-diapause eggs of the silkworm, Bombyx mori. Zool Sci 17: 89-95

Mamiya Y, Sonobe H, Yoshida K, Hara N, Fujimoto Y (1995) Occurrence of 3-epi-22-deoxy-20-hydroxyecdysone and its phosphoric ester in diapause eggs of the silkworm, Bombyx mori. Experientia 51: 363-367

Motta LS, da Silva WS, Oliveira DMP, de Souza W, Machado EA (2004) A new model for proton pumping in animal cells: the role of pyrophosphate. Insect Biochem Mol Biol 34: 19-27

Niimi T, Yoshimi T, Yamashita O (1993) Vitellin and egg-specific protein as metal-binding proteins of the silkworm Bombyx mori. 
J Seric Sci Jpn 62: 310-318

Ohnishi E (1986) Ovarian ecdysteroids of Bombyx mori: Retrospect and prospect. Zool Sci 3: 401-407

Ohnishi E (1990) Ecdysteroids in insect ovaries. In "Molting and Metamorphosis", Ed by E Ohnishi, H Ishizaki, Springer, Berlin, pp 121-129

Ohnishi E, Hiramoto M, Fujimoto Y, Kakinuma K, Ikekawa N (1989) Isolation and identification of major ecdysteroid conjugates from ovaries of Bombyx mori. Insect Biochem 19: 95-101

Raikhel AS, Dhadialla TS (1992) Accumulation of yolk proteins in insect oocytes. Annu Rev Entomol 37: 217-251

Rees HH, Isaac RE (1985) Biosynthesis and metabolism of ecdysteroids and methods of isolation and identification of the free and conjugated compounds. In "Methods in Enzymology, Vol. 111", Ed by JH Low, HC Rilling, Academic Press, London, pp377-410

Scalia S, Sbrenna-Micciarelli A, Sbrenna G, Morgan ED (1987) Ecdysteroid titers and location in developing eggs of Schistocerca gregaria. Insect Biochem 17: 227-236

Sonobe H, Kamba M, Ohta K, Ikeda M, Naya Y (1990) In vitro secretion of ecdysteroids by $\mathrm{Y}$-organ of the crifish, Procambarus clarkii. Experientia 47: 948-952

Sonobe H, Maotani K, Nakajima H (1986) Studies on embryonic diapause in the pnd mutant of the silkworm, Bombyx mori: Genetic control of embryogenesis. J Insect Physiol 32: 215220

Sonobe H, Masumoto T, Tokushige H, Makka T (1997) Developmental changes in accumulation and metabolism of ecdysteroids in diapause eggs and nondiapause eggs of the silkworm, Bombyx mori. In "Advances in comparative endocrinology, Vol. 1" Ed by S Kawashima, S Kikuyama, Monduzzi Editore, Bologne, pp 185-189

Sonobe $H$, Odake $H$ (1986) Studies on embryonic diapause in the pnd mutant of the silkworm, Bombyx mori L. III. Accumulation of alanine in the diapause eggs. Roux's Arch Dev Biol 193: 414417

Sonobe $\mathrm{H}$, Tokushige $\mathrm{H}$, Makka T, Tsutsumi H, Hara N, Fujimoto $\mathrm{Y}$ (1999) Comparative studies of ecdysteroid metabolism between diapause eggs and non-diapause eggs of the silkworm, Bombyx mori. Zool Sci 16: 935-943
Sonobe H, Yamada R (2004) Ecdysteroids during early embryonic development in silkworm Bombyx mori: metabolism and functions. Zool Sci 21: 503-516

Takesue S, Keino H, Endo K (1976) Studies on the yolk granules of the silkworm, Bombyx mori L.: The morphology of diapause and non-diapause eggs during early developmental stages. Roux's Arch Dev Biol 180: 93-105

Warren JT, Steiner B, Dorn A, Pak M, Gilbert LI (1986) Metabolism of ecdysteroid during the embryogenesis of Manduca sexta. J Liq Chromatogr 9: 1759-1782

Watanabe K, Ohnishi E (1984) The mode of ecdysteroid accumulation in ovaries of Bombyx mori during the pupal and pharate adult period. Zool Sci 1: 114-119

Yamada R, Sonobe H (2003) Purification, kinetic characterization and molecular cloning of a novel enzyme ecdysteroid-phosphate phosphatase. J Biol Chem 278: 26365-26373

Yamada R, Sonobe M, Tatara A, Fujimoto Y, Sonobe H (2002) Activation of ecdysone 22-phosphate: Purification and characterization of ecdysteroid-phosphate phosphatase. In "Conference of European Comparative Endocrinologists", Ed by R Keller, $\mathrm{H}$ Dircksen, D Sedlmeier, H Vaudry, Monduzzi Editore, Bologne, pp 179-183

Yamahama Y, Uto N, Tamotsu S, Miyata T, Yamamoto Y, Watabe S, Takahashi YS (2003) In vivo activation of pro-form Bombyx cysteine protease $(\mathrm{BCP})$ in silkmoth eggs: localization of yolk proteins and BCP, and acidification of yolk granules. J Insect Physiol 49: 131-140

Yamashita O, Indrasith LS (1988) Metabolic fates of yolk proteins during embryogenesis in Arthropods. Dev Growth Differ 30: 337-346

Zhu J, Indrasith LS, Yamashita O (1986) Characterization of vitellin, egg-specific protein and $30-\mathrm{kDa}$ protein from Bombyx eggs, and their fates during oogenesis and embryogenesis. Biochim Biophys Acta 882: 427-436

(Received October 23, 2004 / Accepted November 22, 2004) 